\title{
Article \\ Seawater Effect on Fatigue Behaviour of Notched Carbon/Epoxy Laminates
}

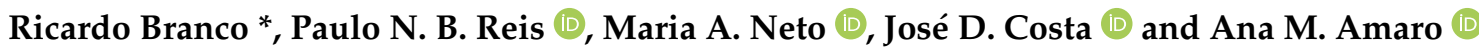 \\ Department of Mechanical Engineering, CEMMPRE, University of Coimbra, 3030-788 Coimbra, Portugal; \\ paulo.reis@dem.uc.pt (P.N.B.R.); augusta.neto@dem.uc.pt (M.A.N.); jose.domingos@dem.uc.pt (J.D.C.); \\ ana.amaro@dem.uc.pt (A.M.A.) \\ * Correspondence: ricardo.branco@dem.uc.pt
}

Citation: Branco, R.; Reis, P.N.B.; Neto, M.A.; Costa, J.D.; Amaro, A.M. Seawater Effect on Fatigue Behaviour of Notched Carbon/Epoxy Laminates. Appl. Sci. 2021, 11, 11939. https:// doi.org/10.3390/app112411939

Academic Editor: Andrea Spagnoli

Received: 19 November 2021

Accepted: 13 December 2021

Published: 15 December 202

Publisher's Note: MDPI stays neutral with regard to jurisdictional claims in published maps and institutional affiliations.

Copyright: (c) 2021 by the authors. Licensee MDPI, Basel, Switzerland. This article is an open access article distributed under the terms and conditions of the Creative Commons Attribution (CC BY) license (https:// creativecommons.org/licenses/by/ $4.0 /)$.

\begin{abstract}
This paper studies the effect of seawater immersion on the fatigue behavior of notched carbon/epoxy laminates. Rectangular cross-section specimens with a central hole were immersed in natural and artificial seawater for different immersion times (0,30 and 60 days), being the water absorption rate evaluated over time. After that, fatigue tests were performed under uniaxial cyclic loading using a stress ratio equal to 0.1 . After the tests, the optical microscopy technique allowed the examination of the failure micro-mechanisms at the fracture surfaces. The results showed that saturation appeared before 30 days of immersion and that water absorption rates were similar for natural and artificial seawater. The S-N curves showed that the seawater immersion affects the fatigue strength, but there were no relevant effects associated with the type of seawater. Moreover, it was also clear that fatigue life was similar for long lives, close to 1 million cycles, regardless of the immersion time or the type of seawater. On the contrary, for short lives, near 10 thousand cycles, the stress amplitude of dry laminates was 1.2 higher than those immersed in seawater. The failure mechanisms were similar for all conditions, evidencing the fracture of axially aligned fibres and longitudinal delamination between layers.
\end{abstract}

Keywords: composite laminates; open holes; seawater effect; fatigue life; mechanical testing

\section{Introduction}

Composite materials are used in various engineering applications, such as marine, aerospace, civil, offshore, sports, and automobile industries, due to their high specific strength and stiffness, as well as their high fatigue and corrosion resistance. In particular, carbon (CFRP), glass (GFRP) and Kevlar (KFRP) fibre-reinforced polymer composites are being increasingly used in several industrial applications. Therefore, traditional materials such as steel and aluminium alloys have been replaced by fibre-reinforced composites, and this trend is likely to continue in the near future because of their outstanding mechanical properties [1]. Nevertheless, in several engineering applications, it is expected that these materials will be exposed to hostile environmental conditions, with consequent degradation of their load-bearing capacity, which can significantly affect their mechanical properties, reducing long-term durability. As is well-known, the oceans cover more than $70 \%$ of the Earth's surface and represent an important source of energy. During the last few years, the use of composite materials in the marine industry has increased significantly [2]. The marine environment, like seawater, involves adverse conditions that lead to a decrease in the structural integrity of composite components, with fatigue behaviour being one of the main concerns in the design of marine structures subjected to cyclic loads, with direct implications on maintenance costs [3]. Ocean energy devices made of composite materials operate in a very severe environment, and the selected materials must be thoroughly qualified to reduce the risk of failure in service [4]. Water uptake in this family of materials as well as its effect on their mechanical behaviour, treated as an uncoupled phenomenon, has been widely studied [5-12]. According to Aoki et al. [13], the water is responsible for 
irreversible damage. The chemical changes induced in the matrix can promote serious degradation of mechanical properties, and debonding at the fibre/matrix interface and delamination. When delamination appears on the laminate, there is a reduction in the strength, stiffness, and fatigue life of the laminate, which can lead to catastrophic failure of the entire structure. Apicella et al. [14-16] investigated the hygrothermal effect in the fatigue lifetime of CFRP composite laminates. They observed three absorption modes: bulk dissolution of water in the polymer network, moisture absorption onto the surface of vacuoles, and hydrogen bonding between polymer hydrophilic groups and water. Due to the chemical reactions between the water molecules and the matrix, the water acts as a plasticizer, and the composite becomes softer because the matrix tends to be more flexible [13]. As one of the most common reasons for material breaking down, fatigue failure needs to be investigated as a vital property in the design of composites subjected to cyclic loads [17]. Although there are some studies on the use of composites in adverse conditions, the durability of CFRP composites exposed to moisture or wet conditions needs further research to make them applicable to external applications with limited monitoring or inspection [18].

Due to their specific characteristics, composite materials are excellent candidates for developing reliable lightweight components and structures that are often subjected to cyclic loads. Under these peculiar service conditions, such materials are susceptible to progressive damage accumulation over the entire fatigue life. Due to the degradation of the mechanical properties of a laminate subjected to fatigue loading, a final failure can occur after a certain number of cycles [19]. Gonabadi et al. [20] studied the fatigue failure of materials immersed in seawater and concluded that the total failure takes place quickly after the appearance of the first crack. Kafodya et al. [21] studied the effect of CFRP plates immersed on water and seawater at room temperature. They observed a significant effect on the variation of the mechanical properties of the material. Koshima et al. [22] analysed the response of CFRP laminates immersed in seawater and observed that fatigue durability is strongly affected by the stress ratio and the deterioration of the fibre/matrix interface strength. According to Weitsman and Elhia [23], the coupling between mechanically induced microcracks in the composite and the suction of water into the capillary channels has an important role in the fatigue life of the component. Similar conclusions have been found by Boisseau et al. [4] who reported a significant reduction in the fatigue lifetime due to seawater ageing. Kotsikos et al. [24] evaluated the effect of seawater absorption on fatigue damage accumulation in a GFRP laminate and reported a strong influence of water absorption on the damage accumulation of such materials under cyclic loading. In the study by Kensche [25], who compared the fatigue behaviour of dry and saturated glass/epoxy samples, it was observed that there was a smaller lifetime expectancy at higher strain rates for wet samples, while at lower strain levels the fatigue strength increased. Meng et al. [3] analysed the effect of moisture ingress on the bending fatigue of laminated composites and concluded that the lifetime expectancy was significantly reduced, more precisely from $80 \%$ of the ultimate flexural strength (UFS) to $65 \%$ of the ultimate flexural strength. Ramirez et al. [26] investigated the degradation of critical components made of polymer matrix composites for naval applications immersed in distilled and seawater. They noted a significant reduction in transverse strength for the water-immersed composites when compared to the control samples. The negative effect of environmental factors, such as seawater, on the physical and mechanical properties of composite materials has been addressed by many authors $[3,27,28]$.

Another important aspect in the design of composite laminates subjected to cyclic loading is the existence of geometric discontinuities. There are several engineering structures where it is necessary to introduce holes to accommodate electrical wires, bolt and rivet holes, and access holes for routing of cables and hydraulic pipes, or for assembly and maintenance purposes, which can cause high-stress gradients, speeding up the fatiguecrack growth rates $[29,30]$. These holes or notches produce stress concentration effects and can therefore affect the structural integrity. Although composite materials have high 
specific strength and high specific stiffness, they are not isotropic, so the stress distribution is dependent on the loading orientation [31]. Erçin et al. [32] studied the effect of the central hole size on the strength of composite laminates subjected to tension/compression. An interesting outcome was that the specimens with open holes developed transverse cracks in the top layer from the notch boundary. Furthermore, at higher applied stresses, the cracks also emanated from the free edges. Santos et al. [33] evaluated the low-velocity impact response of holed GFRP laminates. They observed that there was a significant influence on fatigue life in notched samples compared to the control samples. However, according to the authors' knowledge, there are no studies addressing the fatigue response of composite components with holes immersed in seawater. For this purpose, fatigue tests were carried out for different immersion times ( 0,30 and 60 days) into seawater, using specimens produced from carbon/epoxy composites containing open holes. The difference observed in the fatigue life between immersion into natural and artificial seawater was also be analysed. The fatigue life results are discussed in terms of S-N curves, and the damage evolution is evaluated in terms of stiffness modulus.

\section{Materials and Methods}

The material used in this study was a carbon-fibre-reinforced epoxy composite, which was prepared via autoclave/vacuum-bag moulding using a unidirectional high-strength carbon prepreg (Texipreg HS 160 REM). The plates were produced with 12 layers, arranged in a stacking sequence of $(0 / 45 / 90 /-45 / 0 / 90)_{s}$, corresponding to a thickness of $1.8 \mathrm{~mm}$ and $\mathrm{V}_{\mathrm{f}}=40 \%$. More details about the manufacturing process can be found in [34]. As shown in Figure 1, the specimens were obtained from these plates and consisted of a rectangular cross-section geometry with a $3 \mathrm{~mm}$-diameter central hole. The hole was drilled via twist drill bits for composite materials.

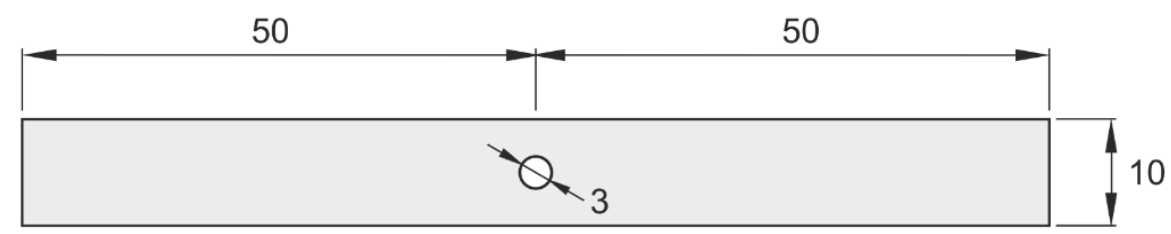

Figure 1. Specimen geometry used in the fatigue tests (units: $\mathrm{mm}$ ).

After production of the samples, they were immersed into natural and artificial seawater for 30 and 60 days. For this purpose, artificial seawater was made following the recommendations outlined in the ASTM D1141 standard [35] with a pH of 8.2 and a $\mathrm{NaCl}$ concentration (i.e., weight/volume ratio) equal to $2.45 \%$. The synthetic compounds in the solution are shown in Table 1 . To simplify the preparation, compounds whose concentration was less than $0.2 \mathrm{~g} / \mathrm{L}$ were not included. The natural seawater was collected from the estuary of the port of Figueira da Foz, a coastal village in central Portugal bathed by the Atlantic Ocean. After the exposure time, the samples were superficially dried and submitted to the experimental programme.

Table 1. Artificial seawater compounds (g/L).

\begin{tabular}{ccccc}
\hline $\mathbf{N a C l}$ & $\mathrm{MgCl}_{2}$ & $\mathrm{Na}_{2} \mathbf{S O}_{4}$ & $\mathrm{CaCl}_{2}$ & $\mathrm{KCl}$ \\
\hline 24.53 & 5.20 & 4.09 & 1.16 & 0.695 \\
\hline
\end{tabular}

Fatigue tests were carried out in a $100 \mathrm{kN}$ servo-hydraulic tension-compression machine, under uniaxial constant-amplitude loading, using sinusoidal waves, with a stress ratio (R) equal to 0.1 and a frequency of $10 \mathrm{~Hz}$ (see Figure 2). The applied normal stress amplitudes (calculated based on the net cross-section, i.e., dividing the applied force by the net cross-section area) and the corresponding fatigue lives for the tested specimens are summarised in Table 2 . The stiffness modulus variations were evaluated directly from the 
vertical displacement of the crosshead relative to the zero-load displacement. Finally, after the fatigue tests, fracture surfaces were examined by optical microscopy, LEICA MC120 HD DM4000 M LED, to identify the dominant damage mechanisms.

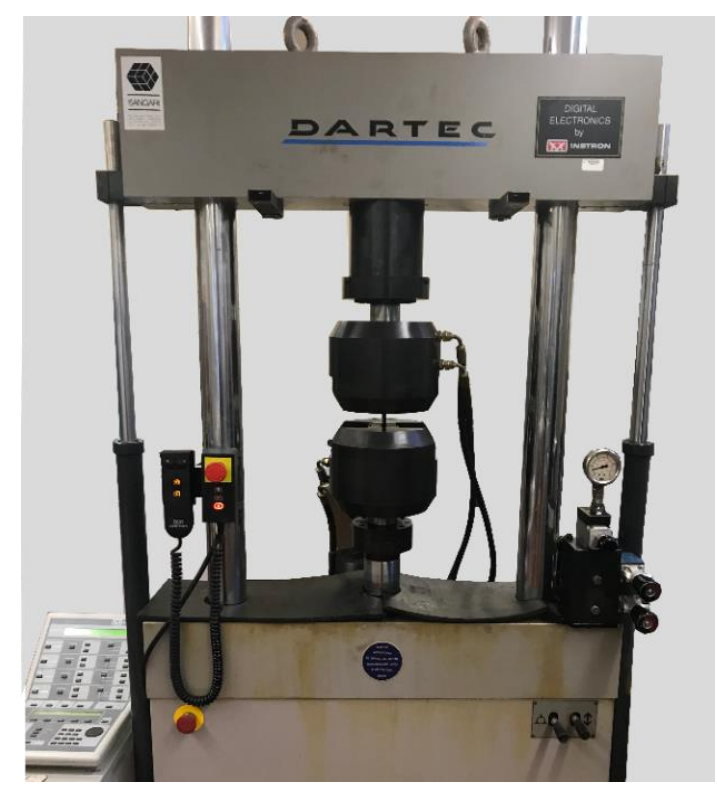

Figure 2. Experimental apparatus used in the uniaxial stress-controlled fatigue tests.

Table 2. Summary of fatigue tests.

\begin{tabular}{|c|c|c|c|c|c|c|}
\hline Test & 1 & 2 & 3 & 4 & 5 & 6 \\
\hline \multicolumn{7}{|c|}{ 0-day immersion } \\
\hline$\sigma_{\mathrm{a}}(\mathrm{MPa})$ & 216.0 & 228.4 & 252.9 & 261.1 & 277.4 & 308.6 \\
\hline $\mathrm{N}_{\mathrm{f}}($ cycle $)$ & $3,325,233$ & $1,177,063$ & 374,299 & 138,655 & 62,318 & 18,267 \\
\hline \multicolumn{7}{|c|}{ 30-days immersion (natural sea water) } \\
\hline$\sigma_{\mathrm{a}}(\mathrm{MPa})$ & 221.1 & 244.9 & 252.9 & 261.1 & 277.8 & 293.0 \\
\hline $\mathrm{N}_{\mathrm{f}}($ cycle $)$ & 231,596 & $1,065,134$ & 373,244 & 10,953 & 2337 & 8521 \\
\hline \multicolumn{7}{|c|}{ 30-day immersion (artificial sea water) } \\
\hline$\sigma_{\mathrm{a}}(\mathrm{MPa})$ & 212.0 & 228.3 & 244.5 & 261.0 & 270.7 & 277.2 \\
\hline $\mathrm{N}_{\mathrm{f}}$ (cycle) & $3,166,016$ & 42,577 & 259,469 & 161,689 & 2282 & 3241 \\
\hline \multicolumn{7}{|c|}{ 60-day immersion (natural sea water) } \\
\hline$\sigma_{\mathrm{a}}(\mathrm{MPa})$ & 212.0 & 228.4 & 244.9 & 261 & 277.2 & 293.9 \\
\hline $\mathrm{N}_{\mathrm{f}}$ (cycle) & $3,113,244$ & 135,405 & 75,449 & 2965 & 11,265 & 1849 \\
\hline \multicolumn{7}{|c|}{ 60-day immersion (artificial sea water) } \\
\hline$\sigma_{\mathrm{a}}(\mathrm{MPa})$ & 212.0 & 228.5 & 244.8 & 260.9 & 277.3 & 309.9 \\
\hline $\mathrm{N}_{\mathrm{f}}$ (cycle) & $3,243,975$ & 3535 & 648,411 & 24,927 & 7396 & 2151 \\
\hline
\end{tabular}

\section{Results}

Fatigue tests at constant load amplitude were performed in tension $(\mathrm{R}=0.1)$, for which the mean load was inputted by software, and the maximum and minimum axial displacements were constantly monitored. In terms of fatigue test results, the S-N diagram was the main tool used to analyse them. This was based on the stress-life approach and represented the fatigue life dependence on stress. In this study, the total separation of the specimens was adopted as the failure criterion. 
The results obtained for the different test conditions are shown in Figure 3, in terms of stress amplitude versus the number of cycles to failure for the several studied cases, namely 0-day immersion (Figure 3a), 30-day immersion in natural seawater (Figure 3b), 30-day immersion in artificial seawater (Figure 3c), 60-day immersion in natural seawater (Figure 3d), and 60-day immersion in artificial seawater (Figure 3e). The mean curves obtained by linear relationship on log-log scales (via the least squares method) of the experimental results are also superimposed. Regardless of the scatter observed, which is typical of fatigue tests, similar behaviour was observed for all curves and, as expected, the fatigue life increased for lower stress amplitude values.

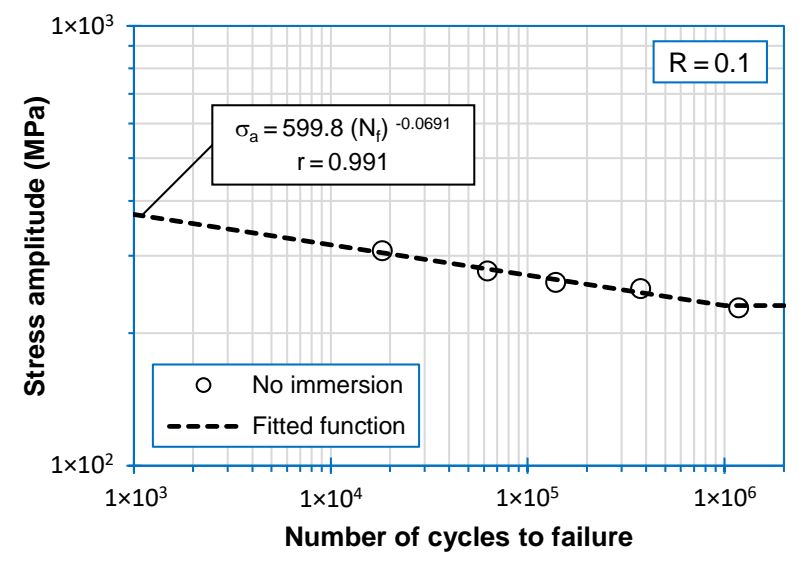

(a)

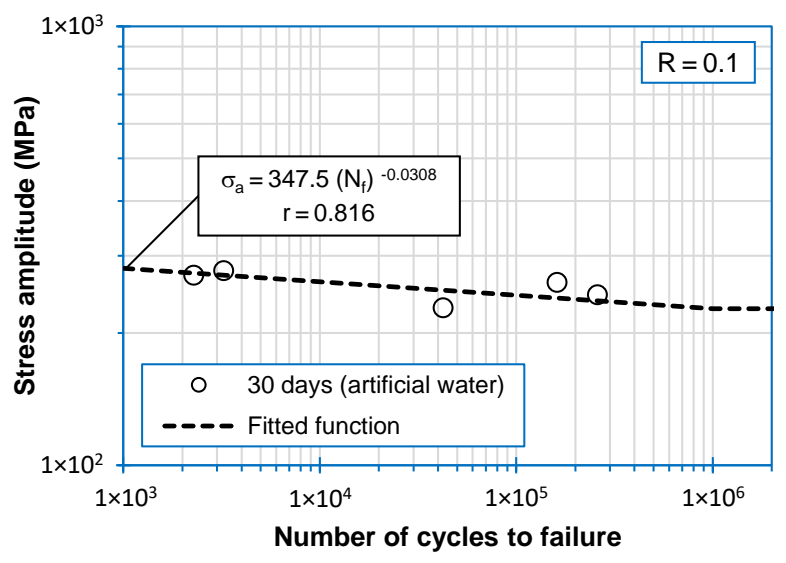

(c)

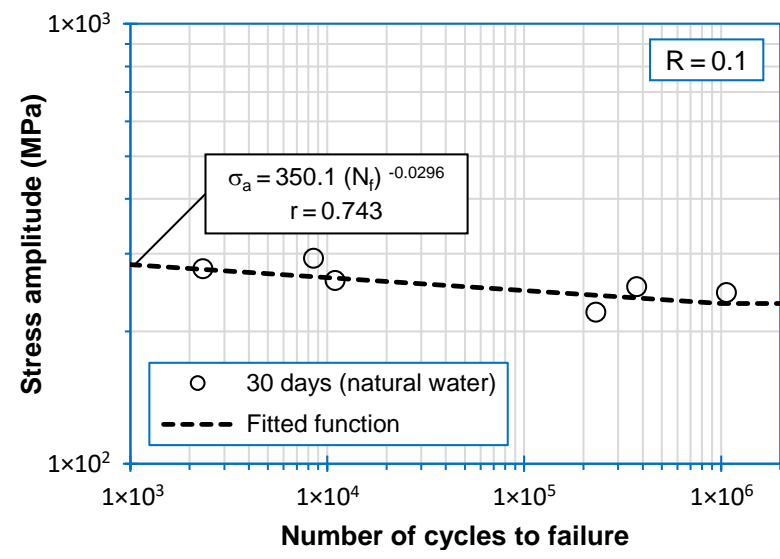

(b)

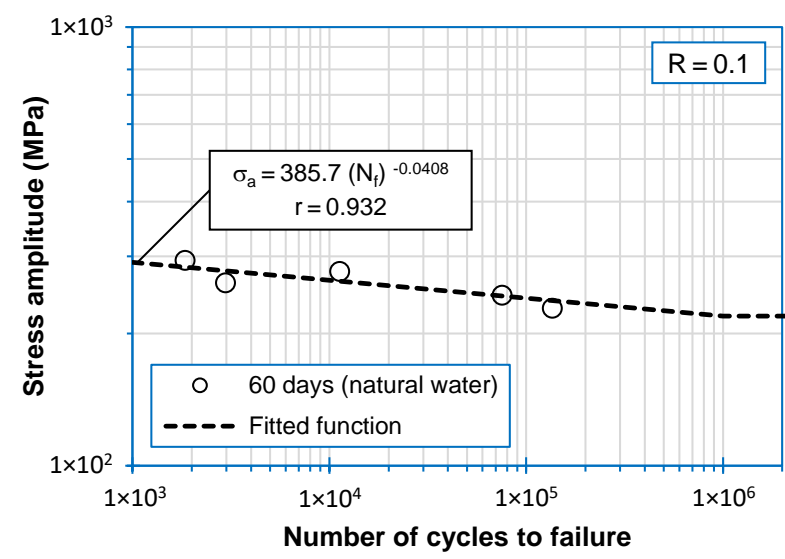

(d)

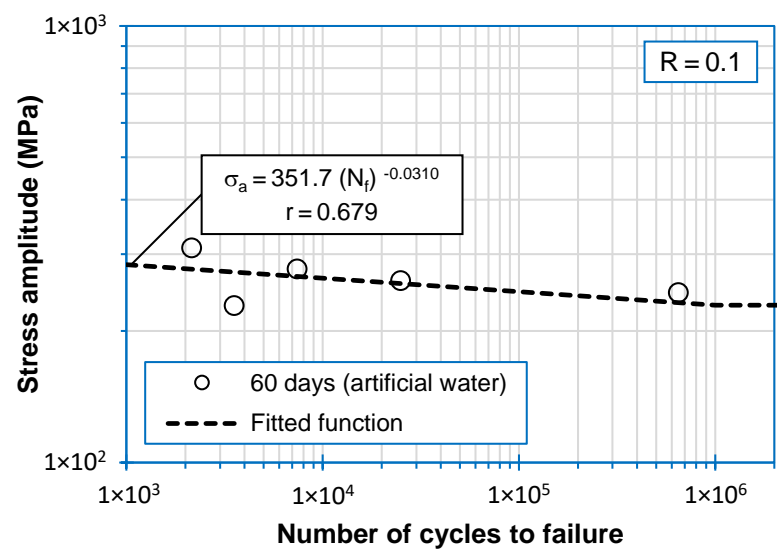

(e)

Figure 3. S-N curve for the series: (a) without seawater immersion, (b) 30-day immersion in natural seawater, (c) 30-day immersion in artificial seawater, (d) 60-day immersion in natural seawater, and (e) 60-day immersion in artificial seawater. 
From all these curves, it is possible to evaluate the effect of exposure time and the type of seawater (natural and artificial seawater) on the fatigue life, comparing the mean curves obtained by the linear relationship of the results obtained. Therefore, this comparison is shown in Figure 4 in terms of exposure time and in Figure 5 in terms of seawater type.
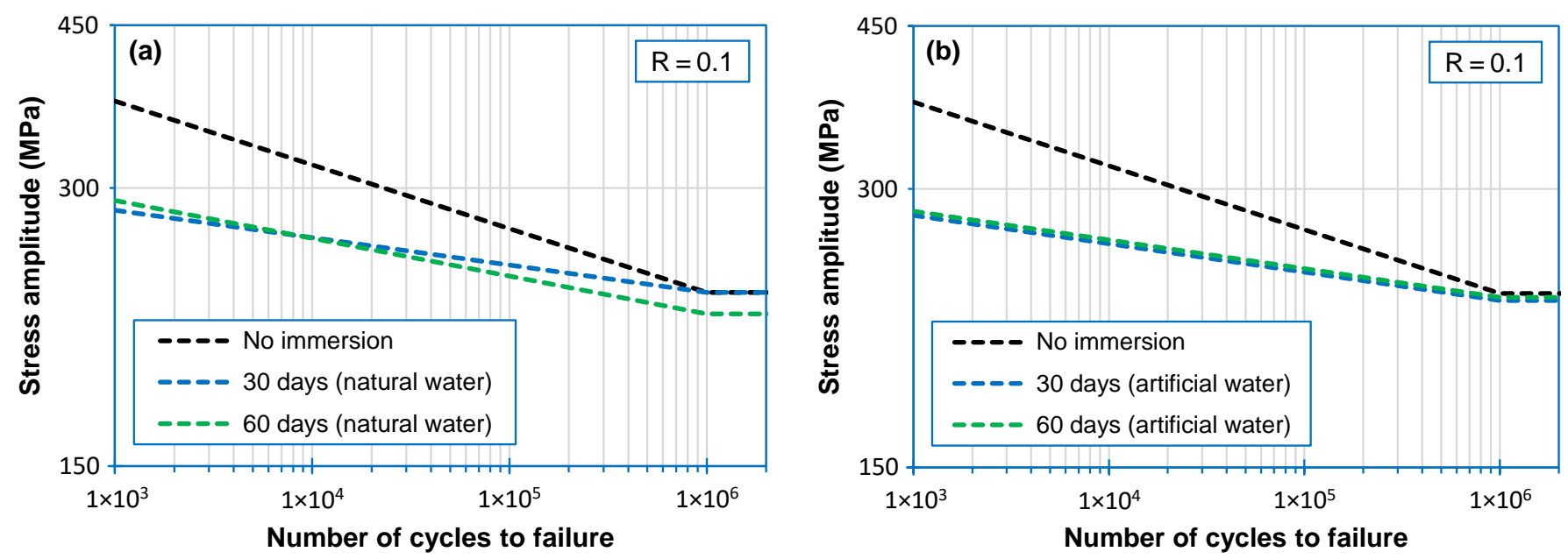

Figure 4. Effect of immersion time on the fatigue life for: (a) natural seawater and (b) artificial seawater.
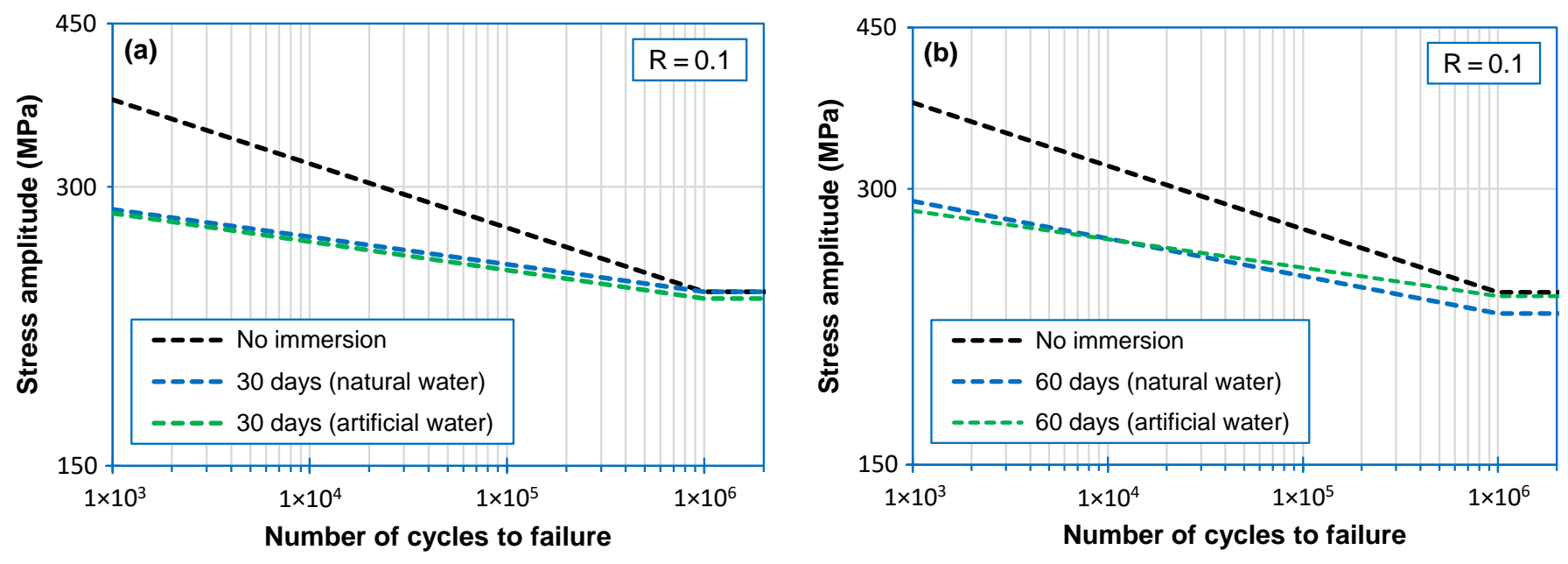

Figure 5. Effect of seawater type on fatigue life for: (a) 30-day immersion; (b) 60-day immersion.

From these figures (Figures 4 and 5), it is possible to conclude that immersion in seawater affects fatigue strength. However, considering the scatter observed in Figure 3 , it is impossible to report any effect of the immersion time for the analysed values (30 and 60 days), and the type of seawater studied (natural and artificial). Therefore, this allows us to conclude that artificial seawater can replace natural seawater because both lead to similar results in terms of fatigue life for the tested conditions. On the other hand, a more detailed analysis shows that in longer lives, for example, the effect of immersion in seawater can be neglected because all specimens have similar fatigue lives. This evidences that the impact of the open holes (and respective stress concentration induced) is superior to the effect of exposure to seawater. However, in short lives, the impact of immersion into seawater significantly affects the fatigue strength. For example, considering a fatigue life of $10^{4}$ cycles, the stress amplitude was 1.2 times higher for dry laminates (control samples) than those immersed in seawater.

These results agree with the studies developed by Kennedy et al. [36], in which the effect of water on the fatigue strength was dependent on the stress level, as in the 
present study. For example, the wet fatigue strength was 20-25\% lower at high stresses, and at high cycles, the wet fatigue strength was $8 \%$ lower [36]. Tual et al. [11] found a decrease in tensile strength of about $20 \%$ to $40 \%$. Still, no significant effect was observed in terms of elastic modulus, which was explained by the lower interfacial adhesion that was assessed by the ILSS tests. Meng et al. [3] observed, for bending fatigue tests, a significant decrease of the fatigue life due to the combination of edge effect and capillary effect. Siriruk and Penumadu [37], for example, observed that the fatigue life of polymeric composites dramatically decreases, by up to $85 \%$, when cyclic loading is applied under immersion conditions, showing a very significant loss of mechanical strength under cyclic loading due to exposure to seawater during the stress cycles. Finally, Meng et al. [38] observed that the moisture diffusivity in CFRP composites immersed in tap water or seawater reveals negligible differences at the same temperature. Moreover, the damage degradation of the fibre/matrix interface in seawater is more significant than in tap water.

According to what is reported in the literature and observed in this study, it is possible to conclude that the decrease of fatigue life is a consequence of the seawater absorption, promoting both matrix cracking and the matrix/fibre interface. To consolidate this evidence, Figure 6 shows the water uptake curves as a function of the immersion time for both solutions (natural and artificial seawater). The percentage weight of water absorbed was evaluated considering the following equation:

$$
\text { Water absorption }(\%)=\left(\frac{m_{W}-m_{D}}{m_{D}}\right) \times 100
$$

where $m_{W}$ is the wet weight and $m_{D}$ is the dry weight.

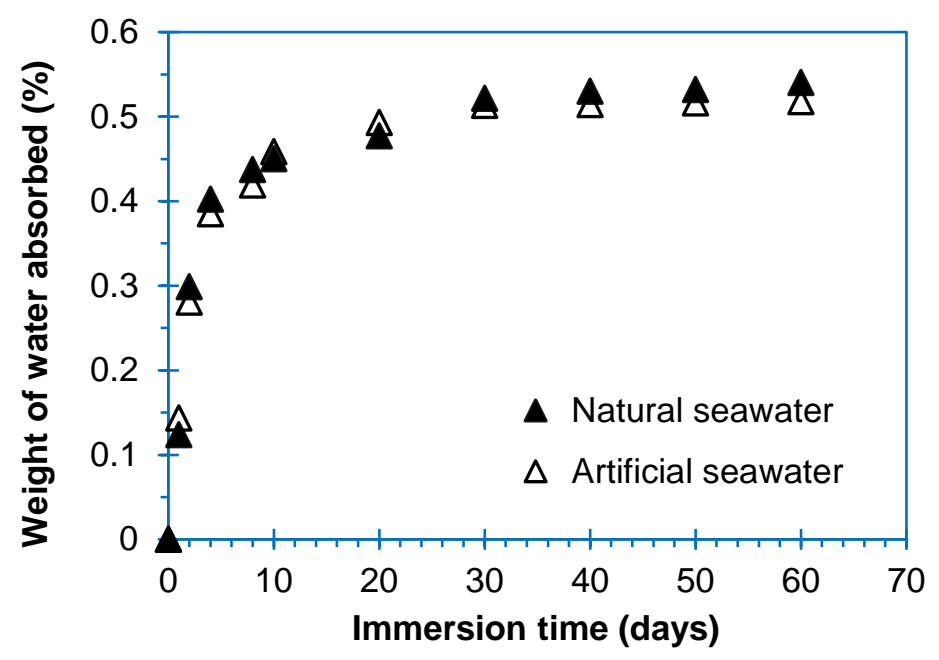

Figure 6. Weight of water absorbed by the composite during seawater immersion ageing.

It was possible to observe that the specimens absorbed water slowly, and the weight remained almost constant after 30 days of immersion; therefore, this shows that saturation had been reached. On the other hand, this figure also denotes no difference between natural and artificial water absorption. Hence, these results support those described above and suggest that fatigue life is similar for natural and artificial seawater. Moreover, the analysed immersion time ( 30 and 60 days) was irrelevant because the samples reached saturation after 30 days of immersion.

According to Ray [39], diffusive and/or capillary processes are the main mechanisms by which moisture can penetrate into polymeric composites. Consequently, in terms of the matrix, reversible and irreversible changes occur in the mechanical properties of thermoset polymers due to water absorption. Plasticisation and swelling are among the most important consequences. On the one hand, the former generally induces plastic deformation and a decrease in the glass transition temperature (Tg). On the other hand, 
the latter is related to the differential strain created by the expansion force exerted by the liquid during the stretching of polymeric chains [40]. For Zheng and Morgan [41], moisture absorption promotes changes in the thermophysical, mechanical and chemical characteristics of the matrix by plasticisation and hydrolysis. Regarding the fibres, the amount of moisture absorbed is completely different from that absorbed by the matrix. Hence, due to different volumetric expansions, stress and deformation fields located in the composite arise [39]. Furthermore, debonding of the fibre/matrix interface also occurs due to possible chemical attacks and mechanochemical effects, such as osmotic pressure. Therefore, all these damage mechanisms caused by moisture affect the loadbearing capacity of the composite and, consequently, lead to the lower fatigue strength observed.

From the data collected throughout the fatigue tests, it was also found that the maximum and minimum axial displacements varied due to the decrease in stiffness (E) caused by fatigue damage [42-45]. Figure 7 plots $E / E_{0}$ versus $N / N_{f}$, for different tests, where $E_{0}$ is the initial value of $E, N$ is the current number of cycles and $N_{f}$ is the number of cycles to failure.

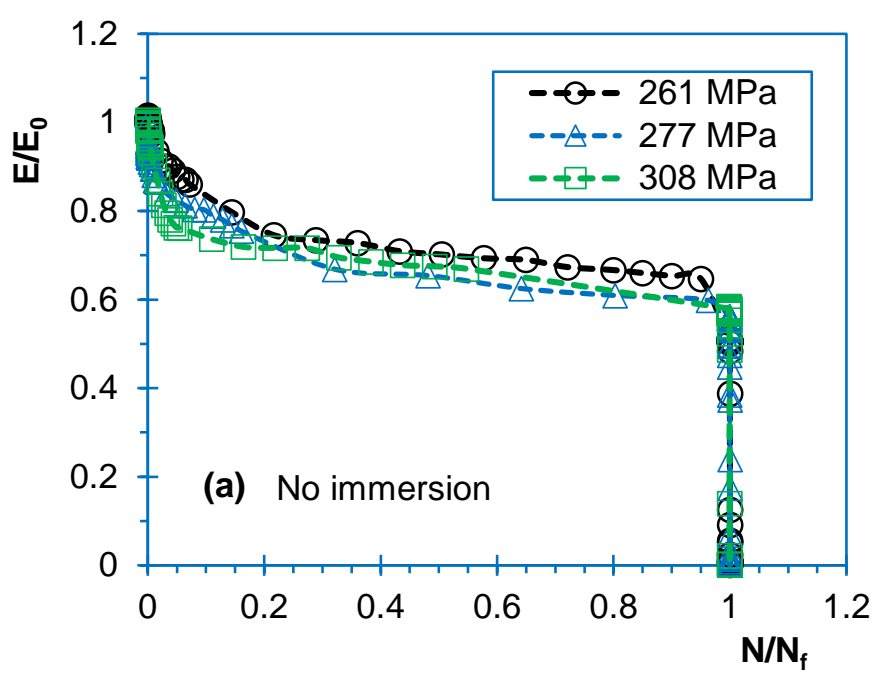

(a)

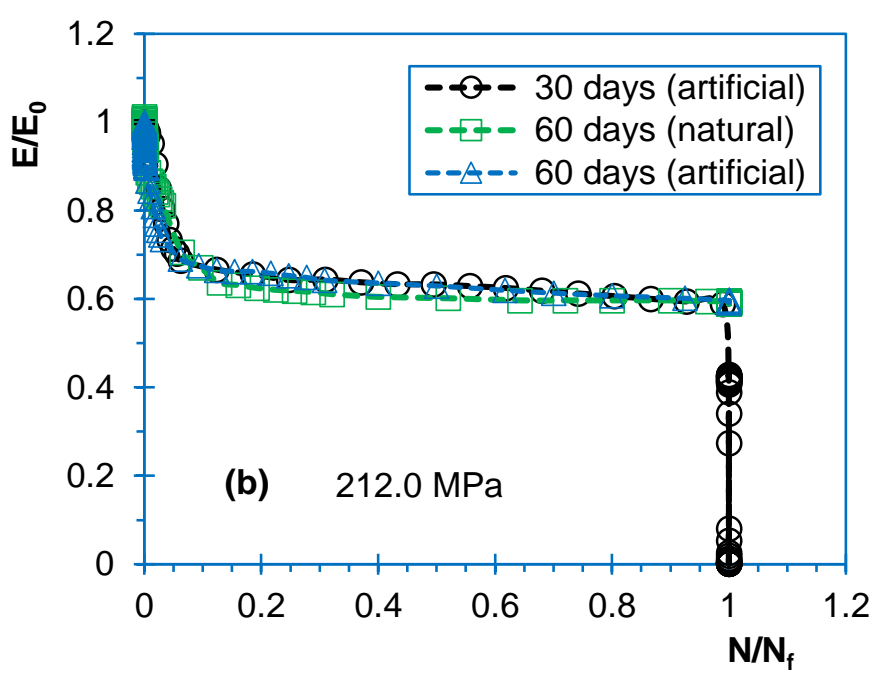

(b)

Figure 7. $\mathrm{E} / \mathrm{E}_{0}$ versus $\mathrm{N} / \mathrm{N}_{\mathrm{f}}$ for tests: (a) with different stress amplitudes using samples not immersed and (b) with different immersion times and types of seawater (natural and artificial seawater).

These curves, which illustrate the evolution of residual stiffness, are, according to the literature, a suitable parameter for fatigue damage assessment. They reflect the degradation that occurs during the fatigue lifetime [42-45]. It is possible to note that after an initial value of $\mathrm{E}$ there is a significant drop in the stiffness modulus during the first $5-30 \%$ of the fatigue life, followed by a second dominant stage where the stiffness modulus slowly decreases until near the final failure. Finally, a third stage occurs during the last $5 \%$ of fatigue life, where the stiffness modulus suddenly drops. According to the open literature, this is a consequence of stress release, temperature rise and internal damage development [44-47]. Regardless of the pre-damage introduced during the drilling process, and despite all the care taken in this procedure, the initial application of the fatigue load introduced matrix cracking and its propagation, or even the propagation of pre-existing cracks, promoting, in this case, the decrease in stiffness modulus observed during the first stage [46]. However, independent of the stress amplitude (Figure 7a), this decrease was higher for wet samples (independent of the immersion time and seawater type) than dry samples due to the damage introduced by the seawater. As reported above, some debonding of the fibre/matrix interface and matrix plasticization (matrix becomes more pliable) were expected. These facilitate the appearance of new matrix cracks and the propagation of pre-existing cracks/defects. In the second stage, the propagation of pre- 
existing cracks and cracks in the matrix contributed to a higher debonding fibre/matrix interface, mainly due to a triaxial stress state developed inside the composite, which became more complex due to the presence of seawater. In this case, the moisture absorbed by the samples created a hydrostatic pressure at the crack tips, which accelerated crack propagation and damage of the matrix [47]. Therefore, while no significant differences were observed for wet samples (independently of the immersion time and seawater type), the dry samples evidenced different second stages. For example, higher stress amplitudes were responsible by lower second stages and longer first stages (see curve for $308 \mathrm{MPa}$ ), proving that higher fatigue loads are responsible for more extensive initial damage over time, but their propagation is faster.

Furthermore, considering the typical dispersion of these curves, the stress amplitudes of $261 \mathrm{MPa}$ and $277 \mathrm{MPa}$ were not sufficiently different to promote significant differences at the level of the second stage's extension. Finally, in the third stage, it was possible to observe that there was a much more significant drop in the stiffness modulus (the transition between the 2nd and the 3rd stages was more abrupt) for wet samples than for dry ones. This behaviour was because the damage severity at the end of the second stage was higher for wet samples.

Figure 8 shows typical fracture surfaces obtained after fatigue tests for all conditions considered in this study. The failure aspects were similar for all conditions, evidencing that the damage mechanism was dominated by the fracture of axially aligned fibres accompanied by longitudinal delamination between layers. The normal stresses that cause some debonding between the fibres and the matrix were also observed for layers aligned in the $90^{\circ}, 45^{\circ}$ and $-45^{\circ}$ directions. This fracture morphology agrees with the literature [48,49]. Regarding the samples immersed in seawater, and regardless the water's nature (artificial or natural), no change in the damage mode was observed due to the pliability of the matrix or due to the existence of debonding in the fibre/matrix interface. In that case, only the damage spread faster.

(a)
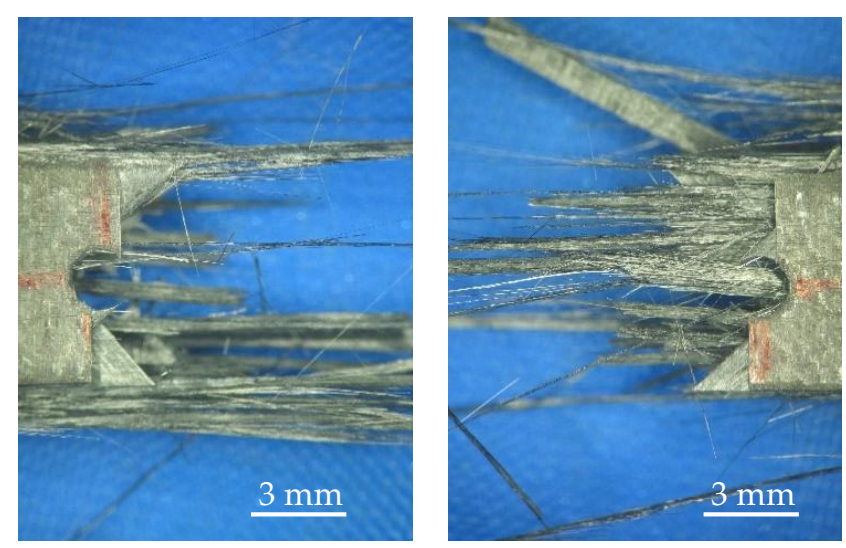

(b)
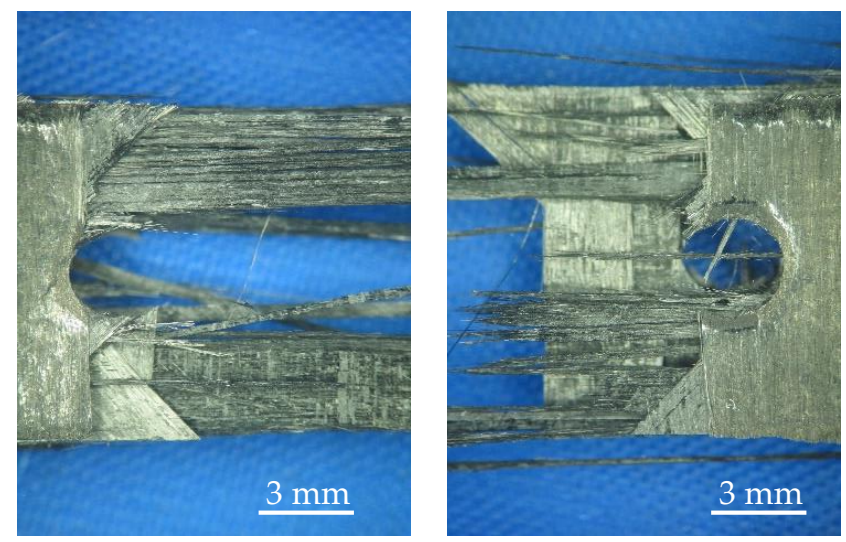

Figure 8. Cont. 
(c)
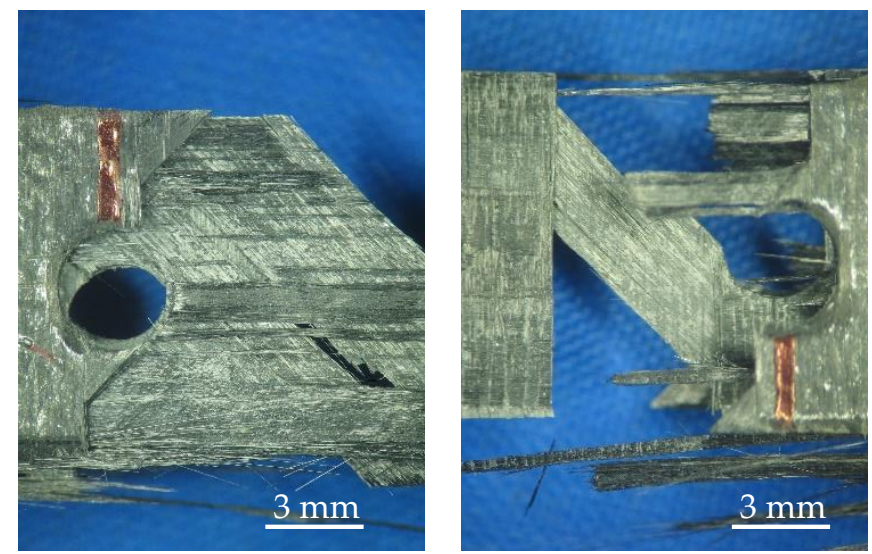

(d)
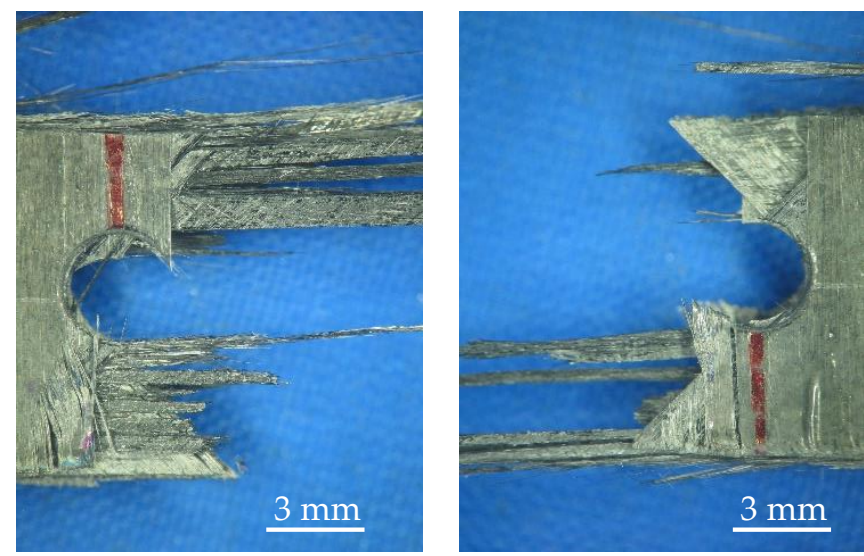

Figure 8. Fracture surfaces for: (a) dry sample (control sample), (b) sample immersed 30 days in natural seawater, (c) sample immersed 60 days in natural seawater, and (d) sample immersed 60 days in artificial seawater.

\section{Conclusions}

This paper studied the effect of seawater immersion on the fatigue behaviour of notched carbon/epoxy laminates. The experimental programme was conducted using rectangular cross-section specimens with a central hole. Specimens were immersed in seawater for different immersion times (0,30 and 60 days). Fatigue tests were performed under uniaxial cyclic loading, under the load-control mode, using a stress ratio equal to 0.1. After the tests, fracture surfaces were examined to identify the main failure mechanisms. The following conclusions can be drawn:

- Water absorption occurred slowly, and the weight remained almost constant after 30 days of immersion, which suggests that saturation had been reached, either for natural or artificial seawater.

- Seawater immersion affected the fatigue strength. However, considering the scattered nature of the fatigue phenomenon, the roles of the immersion time (30 and 60 days) or the type of seawater (natural or artificial) were not relevant.

- The effect of seawater for long lives, close to 1 million cycles, can be neglected. On the contrary, as the lifetime decreases, the reduction of fatigue strength increases progressively. For fatigue lives of $10^{4}$ cycles, the stress amplitude was 1.2 higher in dry laminates than in wet laminates.

- The failure mechanisms were similar for all conditions, evidencing the fracture of axially aligned fibres and longitudinal delamination between layers. Debonding between the fibres and matrix produced by normal stresses was also observed for layers aligned in the $90^{\circ}, 45^{\circ}$ and $-45^{\circ}$ directions. 
Author Contributions: R.B. and P.N.B.R. conceived and designed the study; R.B., P.N.B.R. and A.M.A. performed the tests, and analysed the results; R.B., P.N.B.R., M.A.N., J.D.C. and A.M.A. participated in the research work. Original draft preparation P.N.B.R., A.M.A. and R.B.; writingreview and editing. R.B., P.N.B.R., M.A.N., J.D.C. and A.M.A. All authors have read and agreed to the published version of the manuscript.

Funding: Not applicable.

Institutional Review Board Statement: Not applicable.

Informed Consent Statement: Not applicable.

Data Availability Statement: Not applicable.

Acknowledgments: This research is sponsored by national funds through FCT—Fundação para a Ciência e a Tecnologia, under the project UIDB/00285/2020.

Conflicts of Interest: The authors declare no conflict of interest.

\section{References}

1. Selvaraju, S.; Ilaiyavel, S. Applications of composite in marine industry. J. Eng. Res. Stud. 2011, 2, 89-91.

2. Mouritz, A.P.; Gellert, E.; Burchill, P.; Challis, K. Review of advanced composite structures for naval ships and submarines. Comp. Struct. 2001, 53, 21-41. [CrossRef]

3. Meng, M.; Le, H.; Grove, S.; Rizvi, M.J. Moisture effects on the bending fatigue of laminated composites. Compos. Struct. 2016, 154, 49-60. [CrossRef]

4. Boisseau, A.; Davies, P.; Thiebaud, F. Fatigue behaviour of glass fibre reinforced composites for ocean energy conversion systems. Appl. Compos. Mater. 2013, 20, 145-155. [CrossRef]

5. Diamant, Y.; Marom, G.; Broutman, L.J. The effect of network structure on moisture absorption of epoxy resins. J. Appl. Polym. Sci. 1981, 26, 3015-3025. [CrossRef]

6. Wong, T.C.; Broutman, L.J. Water in epoxy resins Part II. Diffusion mechanism. Polym. Eng. Sci. 1985, 25, 529-534. [CrossRef]

7. Zhou, J.; Lucas, J.P. Hygrothermal effects of epoxy resin. Part I: The nature of water in epoxy. Polymer 1999, 40, 5505-5512. [CrossRef]

8. Popineau, S.; Rondeau-Mouro, C.; Sulpice-Gaillet, C.; Shanahan, M.E.R. Free/bound water absorption in an epoxy adhesive. Polymer 2005, 46, 10733-10740. [CrossRef]

9. Weitsman, Y.J. Anomalous fluid sorption in polymeric composites and its relation to fluid-induced damage. Compos. Part Appl. Sci. Manuf. 2006, 37, 617-623. [CrossRef]

10. Le Duigou, A.; Davies, P.; Baley, C. Seawater ageing of flax/poly(lactic acid) biocomposites. Polym. Degrad. Stab. 2009, 94, 1151-1162. [CrossRef]

11. Tual, N.; Carrere, N.; Davies, P.; Bonnemains, T.; Lolive, E. Characterization of sea water ageing effects on mechanical properties of carbon/epoxy composites for tidal turbine blades. Compos. Part A Appl. Sci. Manuf. 2015, 78, 380-389. [CrossRef]

12. Chilali, A.; Assarar, M.; Zouari, W.; Kebir, H.; Ayad, R. Analysis of the hydro-mechanical behaviour of flax fibre-reinforced composites: Assessment of hygroscopic expansion and its impact on internal stress. Compos. Struct. 2018, 206, 177-184. [CrossRef]

13. Aoki, Y.; Yamada, K.; Ishikawa, T. Effect of hygrothermal condition on compression after impact strength of CFRP laminates. Compos. Sci. Technol. 2008, 68, 1376-1383. [CrossRef]

14. Apicella, A.; Nicolais, L.; Astarita, G.; Drioli, E. Effect of thermal history on water sorption, elastic properties and the glass transition of epoxy resins. Polymer 1979, 20, 1143-1148. [CrossRef]

15. Apicella, A.; Nicolais, L.; Astarita, G.; Drioli, E. Hygrothermal history dependence of equilibrium moisture sorption in epoxy resins. Polymer 1981, 22, 1064-1167. [CrossRef]

16. Apicella, A.; Tessieri, R.; de Cataldis, C. Absorption modes of water in glassy epoxies. J. Membr. Sci. 1984, 18, 211-225. [CrossRef]

17. Behera, A.; Dupare, P.; Thawre, M.M.; Ballal, A. Effects of hygrothermal aging and fiber orientations on constant amplitude fatigue properties of CFRP multidirectional composite laminates. Inter. J. Fatigue 2020, 136, 105590. [CrossRef]

18. Behera, A.; Vishwakarma, A.; Thawre, M.M.; Ballal, A. Effect of hygrothermal aging on static behavior of quasi-isotropic CFRP composite laminate. Compos. Commun. 2020, 17, 51-55. [CrossRef]

19. Carraro, P.A.; Maragoni, L.; Quaresimin, M. Prediction of the crack density evolution in multidirectional laminates under fatigue loadings. Compos. Sci. Techn. 2017, 145, 24-39. [CrossRef]

20. Gonabadi, H.; Oila, A.; Yadav, A.; Bull, S. Fatigue damage analysis of GFRP composites using digital image correlation. J. Ocean. Eng. Mar. Energy 2021, 7, 25-40. [CrossRef]

21. Kafodya, I.; Xian, G.; Li, H. Durability study of pultruded CFRP plates immersed in water and seawater under sustained bending: Water uptake and effects on the mechanical properties. Compos. Part B 2015, 70, 138-148. [CrossRef]

22. Koshima, S.; Yoneda, S.; Kajii, N.; Hosoi, A.; Kawada, H. Evaluation of strength degradation behavior and fatigue life prediction of plain-woven carbon-fiber-reinforced plastic laminates immersed in seawater. Compos. Part A Appl. Sci. Manuf. 2019, 127, 105645. [CrossRef] 
23. Weitsman, Y.J.; Elahi, M. Effects of Fluids on the Deformation, Strength and Durability of Polymeric Composites-An Overview. Mech. Time-Depend. Mater. 2000, 4, 107-126. [CrossRef]

24. Kotsikos, G.; Evans, J.T.; Gibson, A.G.; Hale, J.M. Environmentally enhanced fatigue damage in glass fibre reinforced composites characterised by acoustic emission. Comp. Part A 2000, 31, 969-977. [CrossRef]

25. Kensche, C.W. Fatigue of composites for wind turbines. Int. J. Fatigue 2006, 28, 1363-1374. [CrossRef]

26. Ramirez, F.A.; Carlsson, L.A.; Acha, B.A. Evaluation of water degradation of vinylester and epoxy matrix composites by single fiber and composite tests. J. Mater. Sci. 2008, 43, 5230-5242. [CrossRef]

27. Ishida, H.; Koening, J.L. A fourier transform infrared spectroscopy study of the hydrolytic stability of silane coupling agents on E-glass fibers. J. Polym. Sci. Pol. Phys. 1980, 18, 1931-1943. [CrossRef]

28. Al-Sabagh, A.; Taha, E.; Kandil, U.; Awadallah, A.; Nasr, G.-A.M.; Taha, M. Monitoring Moisture Damage Propagation in GFRP Composites Using Carbon Nanoparticles. Polymers 2017, 9, 94. [CrossRef]

29. Amaro, A.M.; Reis, P.N.B.; de Moura, M.F.S.F.; Neto, M.A. Influence of open holes on composites delamination induced by low velocity impact loads. Compos. Struct. 2013, 97, 239-244. [CrossRef]

30. Tan, J.L.Y.; Deshpande, V.S.; Fleck, N.A. Failure mechanisms of a notched CFRP laminate under multi-axial loading. Compos. Part A 2015, 77, 56-66. [CrossRef]

31. Alshaya, A.; Rowlands, R. Experimental stress analysis of a notched finite composite tensile plate. Compos. Sci. Techn. 2017, 144, 89-99. [CrossRef]

32. Erçin, G.H.; Camanho, P.P.; Xavier, J.; Catalanotti, G.; Mahdi, S.; Linde, P. Size effects on the tensile and compressive failure of notched composite laminates. Compos. Struct. 2013, 96, 736-744. [CrossRef]

33. Santos, R.A.M.; Reis, P.N.B.; Santos, M.J.; Coelho, C.A.C.P. Effect of distance between impact point and hole position on the impact fatigue strength of composite laminates. Compos. Struct. 2017, 168, 33-39. [CrossRef]

34. Amaro, A.M.; Reis, P.N.B.; Santos, J.B.; Santos, M.J.; Neto, M.A. Effect of the Electric Current on the Impact Fatigue Strength of CFRP Composites. Compos. Struct. 2017, 182, 191-198. [CrossRef]

35. ASTM International. Standard Practice for the Preparation of Substitute Ocean Water; ASTM International: West Conshohocken, PA, USA, 2003; Volume 98, pp. 98-100.

36. Kennedy, C.R.; Leen, S.B.; Brádaigh, C.M.Ó. Immersed Fatigue Performance of Glass Fibre-Reinforced Composites for Tidal Turbine Blade Applications. J. Bio. Tribo. Corros. 2016, 2, 12. [CrossRef]

37. Siriruk, A.; Penumadu, D. Degradation in fatigue behavior of carbon fiber-vinyl ester based composites due to sea environment. Compos. Part B Eng. 2014, 61, 94-98. [CrossRef]

38. Meng, M.; Rizvi, M.J.; Grove, S.M.; Le, H.R. Effects of hygrothermal stress on the failure of CFRP composites. Compos. Struct. 2015, 133, 1024-1035. [CrossRef]

39. Ray, B.C. Temperature effect during humid ageing on the interfaces of glass- and carbon-fibers reinforced epoxy composites. J. Colloid. Interf. Sci. 2006, 298, 111-117. [CrossRef]

40. Barraza, H.J.; Aktas, L.; Hamidi, Y.K.; Long, J.; O’Rear, E.A.; Altan, M.C. Moisture absorption and wet-adhesion properties of resin transfer molded (RTM) composites containing elastomer-coated glass fibers. J. Adhe. Sci. Techn. 2003, 17, 217-242. [CrossRef]

41. Zheng, Q.; Morgan, R.J. Synergistic thermal-moisture damage mechanisms of epoxies and their carbon fiber composites. J. Compos. Mater. 1993, 27, 1465-1478. [CrossRef]

42. Ferreira, J.A.M.; Costa, J.D.M.; Reis, P.N.B. Static and fatigue behaviour of glass-fibre-reinforced polypropylene composites. Theor. Appl. Fract. Mech. 1999, 31, 67-74. [CrossRef]

43. Ferreira, J.A.M.; Costa, J.D.M.; Reis, P.N.B.; Richardson, M.O.W. Analysis of fatigue and damage in glass-fibre-reinforced polypropylene composite materials. Compos. Sci. Technol. 1999, 59, 1461-1467. [CrossRef]

44. Reis, P.N.B.; Ferreira, J.A.M.; Richardson, M.O.W. Fatigue damage characterization by NDT in thermoplastics composites. Appl. Compos. Mater. 2011, 18, 409-419. [CrossRef]

45. Ferreira, J.A.M.; Reis, P.N.B.; Costa, J.D.M.; Richardson, M.O.W. Fatigue behaviour of Kevlar composites with nanoclay-filled epoxy resin. J. Comp. Mat. 2012, 47, 1885-1895. [CrossRef]

46. Barré, S.; Benzeggagh, M.L. On the use of acoustic emission to investigate damage mechanisms in glass-fibre-reinforced polypropylene. Compos. Sci. Technol. 1994, 52, 369-376. [CrossRef]

47. Abdel-Magid, B.; Ziaee, S.; Gass, K.; Schneider, M. The combined effects of load, moisture and temperature on the properties of E-glass/epoxy composites. Compos. Struct. 2005, 71, 320-326. [CrossRef]

48. Reis, P.N.B.; Ferreira, J.A.M.; Costa, J.D.M.; Richardson, M.O.W. Fatigue life evaluation for carbon/epoxy laminate composites under constant and variable block loading. Compos. Sci. Technol. 2009, 69, 154-160. [CrossRef]

49. Reis, P.N.B.; Ferreira, J.A.M.; Antunes, F.V.; Richardson, M.O.W. Effect of interlayer delamination on mechanical behavior of carbon/epoxy laminates. J. Compos. Mater. 2009, 43, 2609-2621. [CrossRef] 